\title{
Surgical extraction of a giant trichobezoar: A rare presentation
}

\section{Ayad Ahmad Mohammed, Sardar Hassan Arif, Reber Haji Qadir, Abdulwahid M. Salih, Fahmi Hussein Kakamad}

\begin{abstract}
Introduction: Trichobezoar occurs when a trichotillomanic patient eats his or her hair after extraction leading to surgical emergency. The aim of this study is to report a case of giant trichobezoar presenting as a abdominal mass and underwent surgical extraction. Case Report: A 14-year-old girl with anorexia, epigastric pain and loss of weight for three month duration. The patient reported history of early satiety and constipation. Abdominal examination showed a palpable, firm, mass in the left hypochondrium. Blood examination revealed hypochromic microcytic anemia with hemoglobin. Computed tomography scan of the abdomen demonstrated intragastric mass with concentric rings with air in between the rings. Endoscopy showed that the stomach was filled with a hairball mixed with food particles that occupy the whole gastric cavity. Through an upper midline incision, a gastrostomy done and the hair ball was extracted. The stomach was closed in double layers using continuous Vicryl and interrupted silk sutures. Post-
\end{abstract}

Ayad Ahmad Mohammed ${ }^{1}$, Sardar Hassan Arif ${ }^{1}$, Reber Haji Qadir $^{2}$, Abdulwahid M. Salih ${ }^{3}$, Fahmi Hussein Kakamad ${ }^{4}$

Affiliations: ${ }^{1}$ University of Duhok, College of Medicine, Department of General Surgery, Duhok, Kurdistan Region, Iraq; ${ }^{2}$ Azadi Teaching Hospital, Azadi Gastroenterology \& Endoscopy Center, Duhok, Kurdistan Region, Iraq; ${ }^{3}$ University of Sulaimani, College of Medicine, Department of General surgery, Sulaimani, Kurdistan Region, Iraq; ${ }^{4}$ Kscien Organization, Hamdi Str. Azadi mall,Sulaimani, Kurdistan Region, Iraq.

Corresponding Author: Fahmi Hussein Kakamad, Doctor City, 11th building, apartment 50, Sulaimani, Kurdistan Region, Iraq; Email: fahmi.hussein@univsul.edu.iq

Received: 08 May 2018

Accepted: 09 June 2018

Published: 04 July 2018 operative period was uneventful. Conclusion: Trichobezoar is a very rare disorder which may lead to surgical emergency.

Keywords: Hair, Trichobezoar, Trichotillomania

\section{How to cite this article}

Mohammed AA, Arif SH, Qadir RH, Salih AM, Kakamad FH. Surgical extraction of a giant trichobezoar: A rare presentation. Int J Case Rep Images 2018;9:100929Z01AM2018.

Article ID: 100929Z01AM2018

$$
* * * * * * * *
$$

doi: 10.5348/100929Z01AM2018CR

\section{INTRODUCTION}

Trichotillomania is a one's tendency to pull his or her hair which may subsequently be eaten and it is currently considered as a type of impulse control disorder [1]. Early diagnosis and prompt management is highly recommended to avoid various medical and surgical emergencies [2]. For a patient to be diagnosed as a case of trichotillomania should met with the following criteria (a) repeated attacks of hair pulling leading to considerable hair loss; (b) tension felt while trying to resist or prior to the attacks (c) gratification, pleasure or subsiding the tension associated with episode completion. (d) crucial impairment or distress in occupational, social or other essential areas of functioning because of the complaint; and (e) providing that hair pulling is not resulted from other mental or medical diseases [1]. Trichobezoar occurs when a trichotillomanic patient eats his or her hair after extraction leading to surgical emergency [3]. It was first described by Baudomant at the end of the eighteen century. Trichobezoar could result from other psychiatric disorders like depression and anxiety [4]. 


\section{EDORIUM Journals}

The aim of this study is to present and discuss a rare case of huge trichobezoar that underwent surgical extraction.

\section{CASE REPORT}

A 14-year-old girl presented to the surgical clinic with anorexia, epigastric pain and weight loss for three month duration. The patient had history of early satiety and constipation. There was no history of nausea and vomiting. The patients had no past medical and surgical history. Examination showed a thin girl with normal vital signs with pallor. Abdominal examination revealed a palpable left hypochondrial mass measuring about $15 \mathrm{~cm}$ $\times 15 \mathrm{~cm}$. The mass was firm, not mobile, non tender, not pulsatile with smooth surface. Blood examination revealed hypochromic microcytic anemia with hemoglobin level of $9 \mathrm{mg} / \mathrm{dl}$. Computed tomography scan of the abdomen demonstrated intragastric mass with concentric rings with air in between the rings, with no other abnormal findings (Figure 1). Endoscopy showed that the stomach was filled with a hairball mixed with food particles that occupy the whole gastric cavity (Figures 2 and 3). The patient diagnosed as having trichobezoar and decision for laparotomy done as the facility and experience for laparoscopy is scanty in our locality. Through an upper midline incision, a gastrostomy done and the hair ball that took the shape of the stomach extracted from the gastric cavity (Figure 4). The stomach was closed in double layers using continuous Vicryl and interrupted silk sutures. The patient admitted for three days and discharged home with uneventful post-operative period. The patient was referred for psychiatric consultation.

\section{DISCUSSION}

A trichobezoar is an extreme rare surgical disorder of young women consisting of a hair ball in the proximal part of the gastrointestinal tract. This may lead to obstruction and subsequent acute abdomen $[1,2]$. The current case was a girl with only 14-year of age. Emotional problems including depression and anxiety account for majority of these cases. The prevalence rate varies from $0.06 \%$ to $4 \%$ [3]. This patient did not show any mood disorder like depression or anxiety.

Trichotillomania (a compulsive urge to pull out one's hair) followed by swallowing the hair (trichophagia) is considered to be one type of pica, which is defined as 'the encessent crying out for and compulsive ingesting of nonfood substances', such as soap, hair, sponge, sand and others [5].

Trichobezoars usually due underlying psychiatric conditions, such as, on the top, trichotillomania, followed by depression, obsessive-compulsive disorder and body dysmorphic disorder [6-8]. However, their prevalence and co-morbidity is unclear. Depending on the case series,

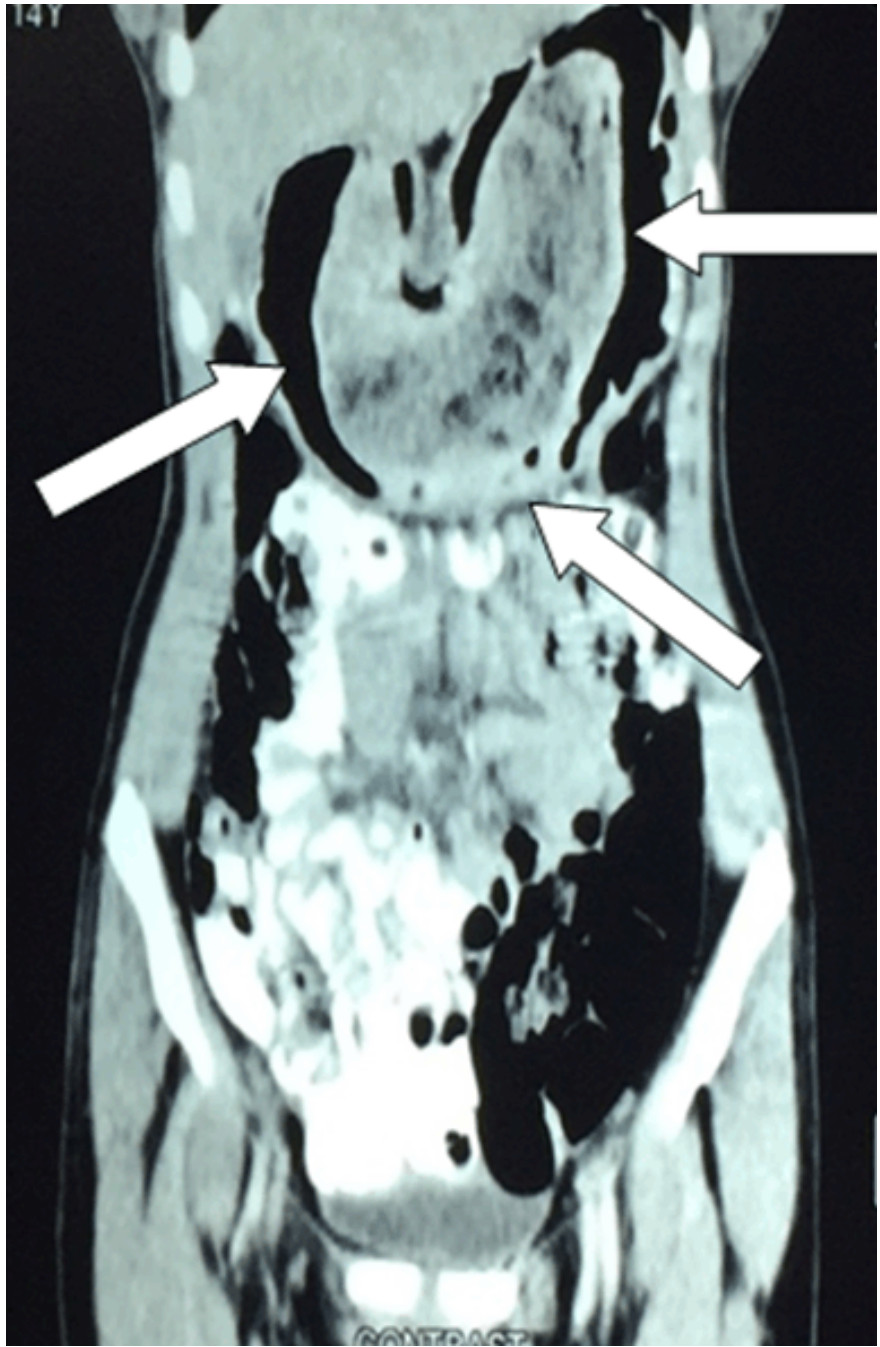

Figure 1: CT scan image showing the hairball inside the gastric cavity (white arrows).

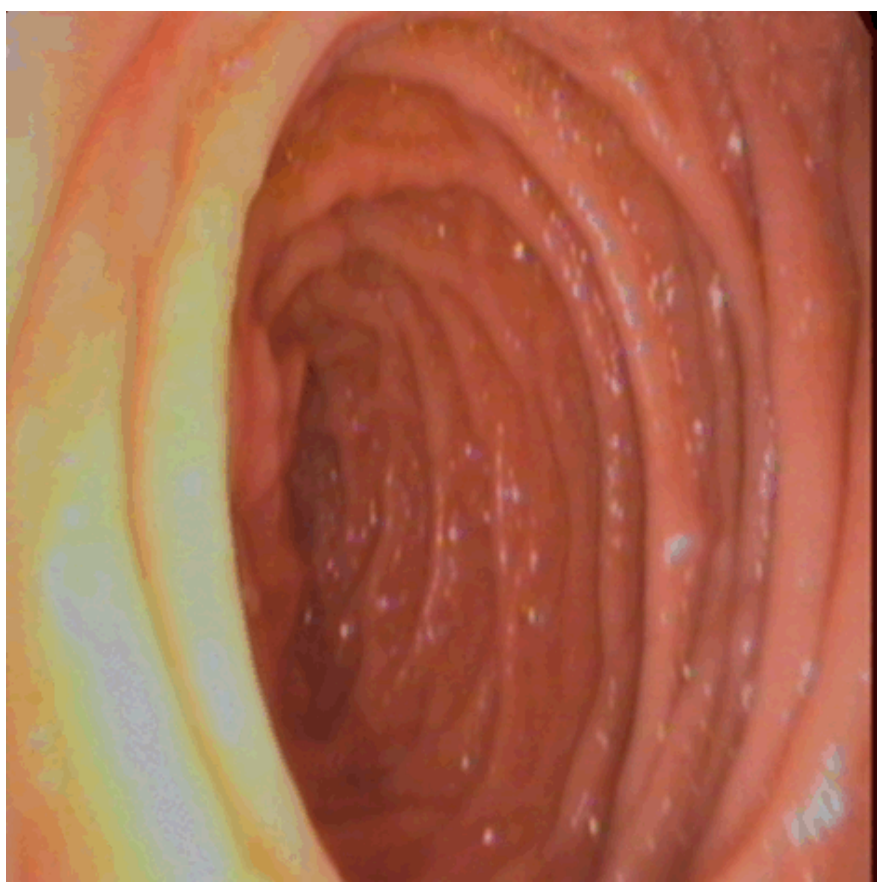

Figure 2: Duodenoscopy showing an empty duodenum with no extension of the hair to the duodenum. 


\section{EDORIUM Journals}

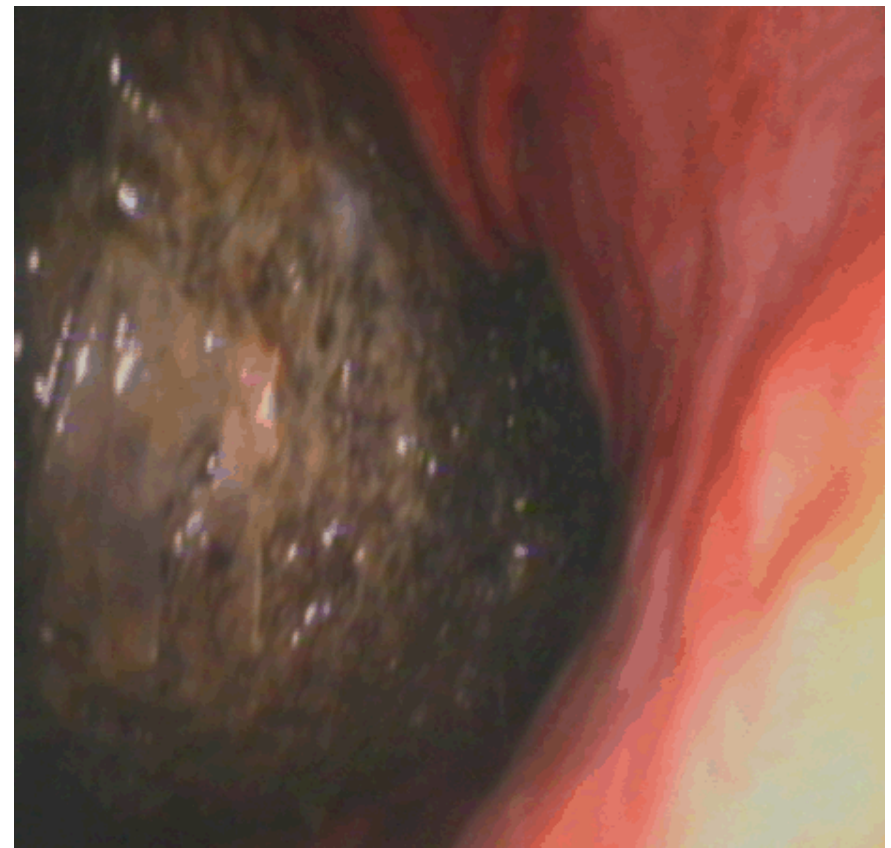

Figure 3: Gastroscopy showing the hair ball that is occupying the gastric cavity.

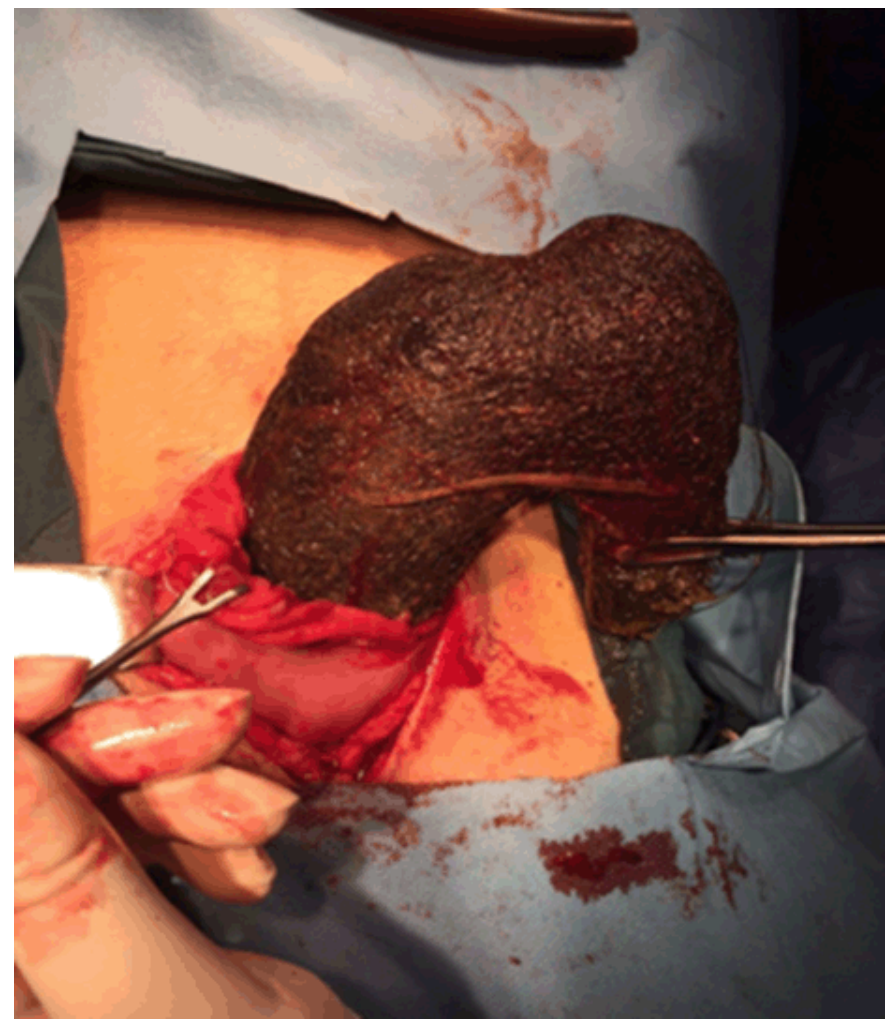

Figure 4: Intraoperative extraction of the hairball from the stomach.

5 to $30 \%$ of the patients with trichotillomania engage in trichophagia while 1 to $37.5 \%$ of these will develop a trichobezoar[9-13].

When eaten, because of its loose surface, hair confronts peristalsis and digestion, and assembles in the mucosal folds. Impaction of hair may result from continuous intake of hair which is usually mixed with mucus and food, leading to trichobezoar[14]. In addition, intestinal obstruction may occur due to pieces of the broken tail [15-17].

Presentation of the trichobezoar cases delays in most of the time, this is might be explained by low index of suspicion. The current case was diagnosed three months after the first complaint and visited several practitioners. The most common presentation is palpable abdominal mass (87.7\%) followed by abdominal pain (70.2\%), gasterointestinal upset (nausea and vomiting) (64.9\%), weight loss and fatigue (38.1\%), constipation or diarrhea (32\%) and rarely haematemesis (6.1\%). Low level of hemoglobin has been reported in about $62 \%$ of the cases [15].

The diagnosis of trichobezoars is based on imaging evidence. Ultrasound is competent in diagnosing of the condition however CT-scan is more authentic in demonstrating bezoar characteristics and increasing the chance of identification of gastrointestinal bezoars. Endoscopy gives the definite diagnosis $[2,6,7]$.

Either laparotomy or laparoscopy is the management strategy of choice according to the facility and experience. Fragmentation of a large foreign body by using monopolar coagulation current and modified needle-knife. This was found to be difficult in most of the case reports, because of the density, size and hardness of the bezoars $[16,18]$. Endoscopy is not recognized as an effective therapeutic option as it needs frequent introduction of the endoscope leading to esophagitis, pressure ulceration and esophageal perforation [19].

\section{CONCLUSION}

Trichobezoar which is one of the complications of trichotillomania is a very rare disorder which may lead to surgical emergency. In cases of acute abdomen pain, laparotomy is necessary. Psychiatric consultation is mandatory to prevent recurrence.

\section{REFERENCES}

1. Diefenbach GJ, Reitman D, Williamson DA. Trichotillomania: A challenge to research and practice. Clin Psychol Rev 2000 Apr;20(3):289-309.

2. Carr JR, Sholevar EH, Baron DA. Trichotillomania and trichobezoar: A clinical practice insight with report of illustrative case. J Am Osteopath Assoc 2006 Nov;106(11):647-52.

3. Duke DC, Keeley ML, Geffken GR, Storch EA. Trichotillomania: A current review. Clin Psychol Rev 2010 Mar;30(2):181-93.

4. Malpani A, Ramani SK, Wolverson MK. Role of sonography in trichobezoars. J Ultrasound Med 1988 Dec;7(12):661-3.

5. Armstrong JH, Holtzmuller KC, Barcia PJ. Gastric trichobezoar as a manifestation of child abuse(1). Curr Surg 2001 Mar;58(2):202-4. 
6. Sehgal VN, Srivastava G. Trichotillomania +/trichobezoar: Revisited. J Eur Acad Dermatol Venereol 2006 Sep;20(8):911-5.

7. Coulter R, Antony MT, Bhuta P, Memon MA. Large gastric trichobezoar in a normal healthy woman: Case report and review of pertinent literature. South Med J 2005 Oct;98(10):1042-4.

8. Pérez E, Sántana JR, García G, et al. Gastric perforation due to trichobezoar in an adult (Rapunzel syndrome). [Article in Spanish]. Cir Esp 2005 Oct;78(4):268-70.

9. Bouwer C, Stein DJ. richobezoars in trichotillomania: Case report and literature overview. Psychosom Med 1998 Sep-Oct;60(5):658-6o.

10. Frey AS, McKee M, King RA, Martin A. Hair apparent: Rapunzel syndrome. Am J Psychiatry 2005 Feb;162(2):242-8.

11. Salaam K, Carr J, Grewal H, Sholevar E, Baron D. Untreated trichotillomania and trichophagia: Surgical emergency in a teenage girl. Psychosomatics 2005 Jul-Aug;46(4):362-6.

12. Christenson GA, Mackenzie TB, Mitchell JE. Characteristics of 60 adult chronic hair pullers. Am J Psychiatry 1991 Mar;148(3):365-70.

13. Christenson GA, Crow SJ. The characterization and treatment of trichotillomania. J Clin Psychiatry 1996;57 Suppl 8:42-7.

14. Vaughan ED Jr, Sawyers JL, Scott HW Jr. The Rapunzel syndrome. An unusual complication of intestinal bezoar. Surgery 1968 Feb;63(2):339-43.

15. Naik S, Gupta V, Naik S, et al. Rapunzel syndrome reviewed and redefined. Dig Surg 2007;24(3):157-61.

16. Tudor EC, Clark MC. Laparoscopic-assisted removal of gastric trichobezoar; a novel technique to reduce operative complications and time. J Pediatr Surg 2013 Mar;48(3):e13-5.

17. Pogorelic Z, Juric I, Zitko V, Britvic-Pavlov S, Biocic M. Unusual cause of palpable mass in upper abdomengiant gastric trichobezoar: Report of a case. Acta Chir Belg 2012 Mar-Apr;112(2):160-3.

18. Tiago S, Nuno M, João A, Carla V, Gonçalo M, Joana N. Trichophagia and trichobezoar: Case report. Clin Pract Epidemiol Ment Health 2012;8:43-5.

19. Kanetaka K, Azuma T, Ito S, et al. Two-channel method for retrieval of gastric trichobezoar: Report of a case. J Pediatr Surg 2003 Feb;38(2):e7.

\section{Author Contributions}

Ayad Ahmad Mohammed - Substantial contributions to conception and design, Acquisition of data, Analysis and interpretation of data, Drafting the article, Final approval of the version to be published

Sardar Hassan Arif - Substantial contributions to conception and design, Drafting the article, Final approval of the version to be published

Reber Haji Qadir - Analysis and interpretation of data, Drafting the article, Final approval of the version to be published

Abdulwahid M. Salih - Analysis and interpretation of data, Revising it critically for important intellectual content, Final approval of the version to be published Fahmi Hussein Kakamad - Substantial contributions to conception and design, Drafting the article, Final approval of the version to be published

\section{Guarantor of Submission}

The corresponding author is the guarantor of submission.

\section{Source of Support \\ None}

\section{Consent Statement}

Written informed consent was obtained from the patient for publication of this case report.

\section{Conflict of Interest}

Authors declare no conflict of interest.

\section{Copyright}

(C) 2018 Ayad Ahmad Mohammed et al. This article is distributed under the terms of Creative Commons Attribution License which permits unrestricted use, distribution and reproduction in any medium provided the original author(s) and original publisher are properly credited. Please see the copyright policy on the journal website for more information.
Access full text article on other devices

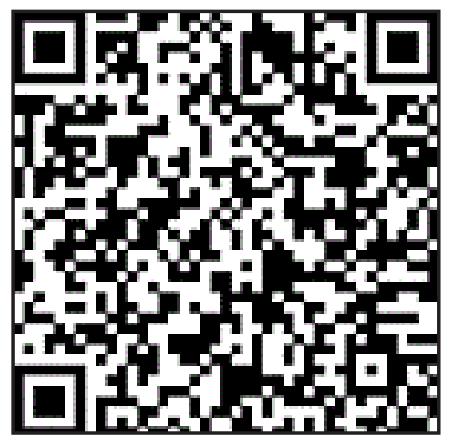

Access PDF of article on other devices

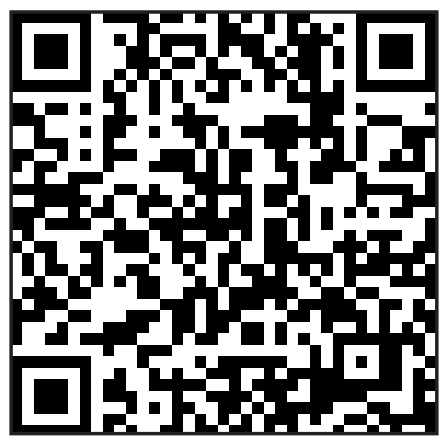

